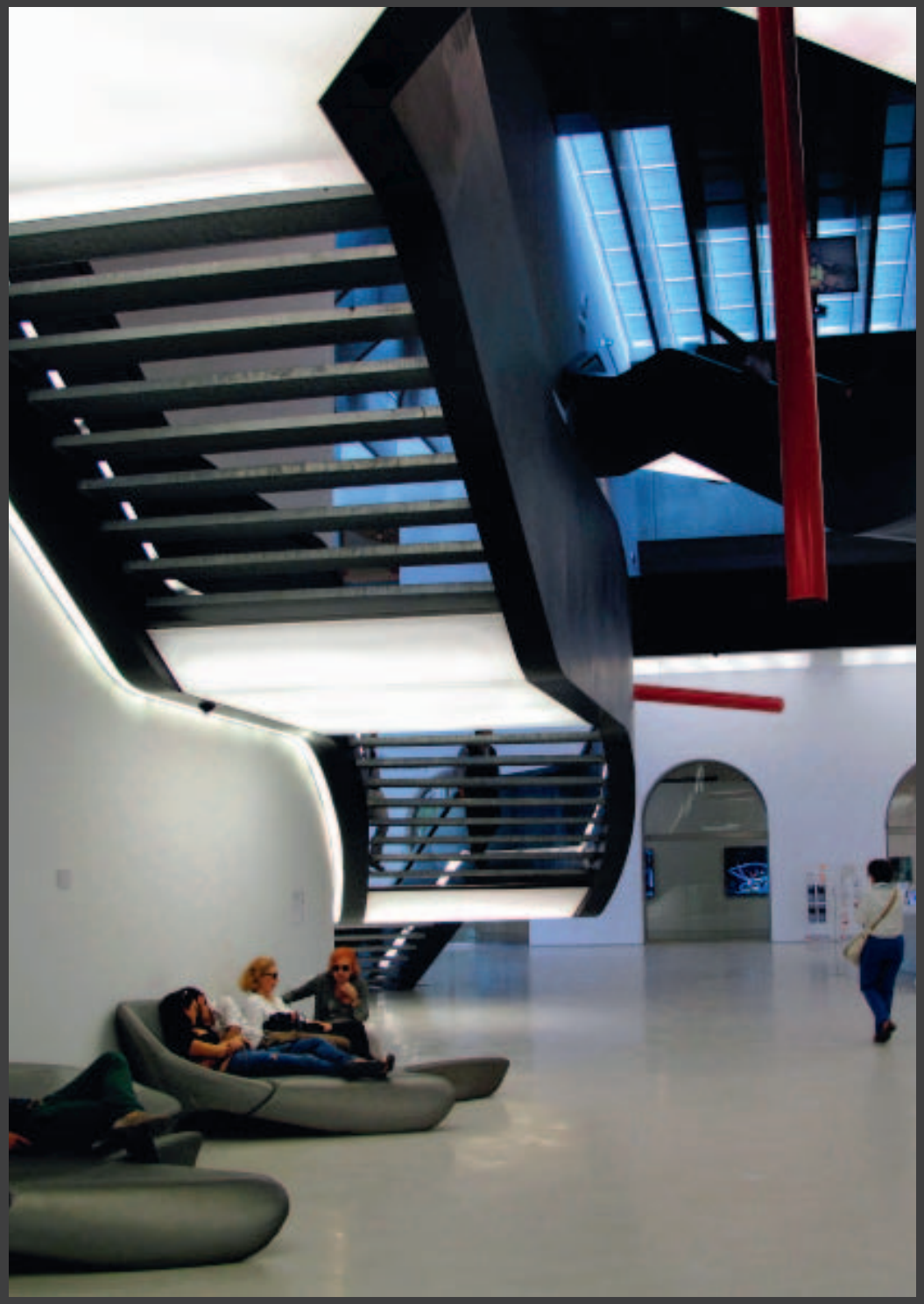

Escaleras del vestíbulo del Museo Nacional de Arte del Siglo XXI (MAXXI), arqt. Zaha Hadid. Roma, Italia. 


\section{El futuro del museo}

Alfonso Castrillón Vizcarra

Este título, que se ha repetido tantas veces en libros y revistas de la especialidad y que puede quizás indicar certeza y confiabilidad en algún plan trazado para el porvenir, podría también presentarse de manera interrogativa ¿cuál es el futuro del museo?, para denotar las dudas e inseguridades acerca de los años que vienen, en este caso las del que escribe. El artículo que sigue tiene el propósito de reflexionar sobre algunos conceptos que inciden en la museología actual, como la "economía de lo inmaterial” propugnada por el liberalismo o la proliferación de museos de "marca" en algunos lugares del mundo, o "museos de autor", con espectaculares espacios que, sin embargo, hacen ver muestras experimentales insignificantes, de acuerdo a las opciones conceptualistas o de art in progress, a los que se suma el relativismo estético puesto en juego hoy día. A los ojos del público informado el arte contemporáneo está en una etapa de agotamiento. En este sentido cabe preguntarse cuál es la función del museo de arte frente a los apremios de la economía, cuál es su opción frente al uso de su patrimonio, o ante la producción artística actual, ¿fomentarla o refugiarse en las tradicionales vanguardias del siglo XX? También, de paso hacer, una confrontación con la situación peruana: ¿en qué fase estamos, respecto a otros países del mundo?

\section{Una teoría para los años setenta}

El primer artículo que leí de Jean Clair ${ }^{1}$, historiador del arte, conservador patrimonial, crítico polemista y miembro de la Academia Francesa desde 2008, fue Erostrate ou le musée en question ${ }^{2}$, brillante texto donde el autor, apoyándose en Malraux y Foucault, caracteriza al museo como pretexto y como contexto. En cuanto al primero, dice Clair que las obras de arte despojadas de las funciones para las que fueron creadas ocupan un lugar en el museo

1 Jean Clair, seudónimo de Gérard Régnier, nacido en Francia el 20 de octubre de 1940.

2 Eróstrato o el museo en cuestión, publicado en L'art de masse n'existe pas, Revue d'Esthetique, París, 1974, $\mathrm{n}^{\mathrm{O}} 3 / 4, \mathrm{p} .185$. 
y no pueden existir sin él, convirtiéndose en "le pretexte nécessaire de toute creation qui, à toute oeuvre, fournit le texte de depart: réserve inépuisable des formes où vient puiser l'artiste, il est aussi le terme ultime où vient s'abîmer, au bout du compte, toute oeuvre"3. Si las academias fueron antaño las que proponían los modelos a imitar, el museo es hoy día el único lugar donde se inscribe la actividad artística. En cuanto al segundo, es decir el contexto, Clair se refiere a él no como el lugar donde está la reserva, los chefs-d'oeuvre, es decir los contenidos que interesan a la historia del arte, sino como contenedor, como support institutionel de son sens. Dice Clair: "Si le musée, pris comme pretéxte, est ce qui vide l'oeuvre de son contenu, pris comme contexte, il est inversement ce qui donne un contenu á tout objet qui franchit son enceinte » El museo es la institución ambigua que por un lado vacía de sus contenidos originales a los objetos y por otro les otorga "el sello" del Arte, con mayúscula. Esta segunda característica, comenta Clair, hace que el museo con todo el prestigio y la autoridad que tiene introduzca en sus salas cualquier tipo de obra y le done la cualidad de Arte.

Pero Clair no se queda en estas constataciones que, después de todo son deducidas de los textos de Malraux; se arriesga a proponer su teoría de la intertextualidad del museo que consiste en "un type de rapport oú l'oeuvre, face au musée, oppose une sorte d'impossibilité d'apprehension, come si les codes en usage ne s'y appliquaient plus".

Para ilustrar su idea Clair recurre a artistas modernos como Boltanski, Jean Le Gac, ${ }^{6}$ o Bartholin que rehúyen el museo, o al ejemplo de la Documenta de Kassel, la Boîte en valise de Duchamp, el Mouse Museum de Oldenburg y por fin al experimento del "ecomuseo" de G.H. Riviére.

Interesante propuesta la de hacer saltar los fusibles del "sentido" dentro del museo, más aplicable a la museografía, es decir al diseño de exposiciones, que al museo mismo ya que su naturaleza será siempre la de repositorio, el lugar donde se exhiben obras fuera de contexto. Es fácil reconocer en la propuesta de Clair ciertos residuos de las ideologías antimuseales del siglo pasado que intentaron desaparecer la institución ${ }^{7}$. Aunque no llegue a tales extremos su propuesta es claramente subversiva y a favor de un nuevo tipo de museo, radicalmente diferente, que favorezca las lecturas intertextuales como fuerzas de disolución de los códigos establecidos, el tiempo burgués entre ellos, considerado en el sentido bursátil de la economía capitalista, el museo de la huida, de la deserción, del nomadismo, un museo éclaté, que escapa a todo lugar definido y a todo tiempo asignado, "et susceptible de rendre l'ouvre á la libre circulation du désir"'.

\section{Una protesta en la época de la globalización}

Después de más de treinta años cayó en mis manos otro libro de Jean Clair titulado La crisis de los museos: la globalización de la cultura ${ }^{9}$, que toma como punto de partida el proyecto de la creación del "Pequeño Louvre" en Abu Dhabi. Este proyecto consiste en la creación de una sucursal del Louvre en la capital federal de los Emiratos Árabes Unidos con una extensión total de 24.000 metros: 6.000 de salas de exposición permanente y 2.000 de temporales. La firma de un contrato por 20 años permitiría el préstamo en un plazo de

3 "El pretexto necesario de toda creación que provee de texto a toda obra de partida: reserva interminable de formas que surten al artista, es también el paradero donde va a terminar, al fin de cuentas, toda obra". Op. cit. p. 189.

4 "Si el museo, tomado como pretexto, vacía a la obra de su contenido, como contexto es, inversamente, el que da un contenido a todo objeto que entra en su recinto". Op.cit. p.192.

5 “...un tipo de relación donde la obra, de cara al museo, opone una especie de imposibilidad de aprehensión, como si los códigos en uso no se aplicaran”. Op. cit. p. 197.

6 Christian Boltanski (París, 1944); Jean Le Gac, (París, 1936).

7 Como la propuesta de Proud'home y su museo necrópolis, o la de Sorel y su idea de que toda obra que apunta al museo está destinada a una muerte segura; o los manifiestos del futurista Marinetti. Op. cit. p.195.

8 “y susceptible de devolver la obra a la libre circulación del deseo”, Op. cit. p.201.

9 Jean Clair, La crisi dei musei. La globalización de la cultura. Editorial Skira, Milano, 2008. 
10 años de 300 obras de las colecciones públicas; luego 200 por los 3 años siguientes y por fin 100 obras por los 3 últimos años. Además un programa anual con más de una decena de exposiciones de obras de las colecciones públicas y asesoramiento de los museos franceses para la compra de obras de la más alta calidad para la colección permanente del museo Louvre-Abu Dhabi. Por todo esto Clair estima que Francia recibiría entre 700 y 1,000 millones de euros. Este hecho sorprendente da lugar a la protesta de Clair y a una serie de consideraciones sobre la cultura global que va explicando con claridad a lo largo del libro.

Los defensores del proyecto alegan que éste contribuirá a la difusión de la cultura universal, valorizará el patrimonio como capital, aprovechará las obras de los abarrotados depósitos nunca antes expuestas, engrosará el presupuesto del Ministerio de Cultura que en los últimos veinte años ha multiplicado sus gastos, etc. Pero estas razones no convencen a Clair y a su grupo que descubren un interés escondido, es decir, favorecer un acuerdo comercial y estratégico para vender aviones civiles y militares a los emiratos. ${ }^{10}$

Clair expone algunos argumentos contundentes como que el Louvre haya hecho tratos con un país donde "no existe ninguna diferencia entre los intereses del Estado y los de la familia reinante" y este acuerdo sin precedentes le sorprende ya que "ningún estado ha alienado sus colecciones, y ni siquiera sus competencias, a favor de los intereses de un privado". ${ }^{11}$ En esta época globalizada donde se asiste a la "desnacionalización" de los servicios públicos (correo, electricidad), se pregunta Clair, "ise puede desnacionalizar las colecciones nacionales?"

Hay otra razón de peso: lo dictado por el Código de Ética del ICOM que precisa que "las colecciones de los museos están constituidas por la comunidad y en ningún caso deben ser consideradas como un activo financiero". ${ }^{12}$ Pero esta recomendación parece no importarles a los responsables del proyecto Louvre-Abu Dhabi, más preocupados en difundir "una política de gestión de la marca, de las competencias y de la imagen", dentro de lo que han dado en llamar "economía del inmaterial". Ahora bien, el sentido tradicional que se le ha dado a la palabra "inmaterial" en los textos artísticos y museísticos ha sido el valor espiritual de las obras únicas y especiales, pero para los financistas y publicistas significa otra cosa: lo inmaterial "se refiere a la moneda fiduciaria constituida por una obra de arte" que deja el lugar en que ha sido conservada (el museo) para entrar como un billete bancario en el circuito económico. Es decir, los gestores de museos convertidos en economistas, han descubierto que hay que movilizar los "activos durmientes" de la institución para acelerar el crecimiento francés. Han pretendido, por otra parte, clasificar las obras de arte que pertenecen a instituciones públicas en dos categorías: los tesoros nacionales y las obras de libre utilización; estas últimas deberán ser registradas como activos en los balances y ser reconocidas como enajenables. ${ }^{13}$ Clair refuerza las ideas sobre la "economía de lo inmaterial" con el caso de lo que él llama "Imperio Guggenheim" extendido hoy día fuera de Estados Unidos en sus sucursales de Bilbao, Venecia y Alemania. ${ }^{14}$

La protesta de Clair se apoya en las obras del patrimonio clásico del Louvre, de pintores fuertemente enraizados en la historia y la tradición cultural francesa, en símbolos como David, Géricault, Delacroix, Courbet, etc. y la lista llega, máximo, a las vanguardias históricas, Matisse, Picasso, Delaunay, etc., contra las que la comercialización que propone el proyecto Abu Dhabi resulta una profanación y un sacrilegio. Como francés le duele que

10 Clair, Jean. Op. cit. p.43

11 Ibidem, p. 46

12 Ibidem, p. 48

13 Ibidem, p. 50

14 Ibidem, p. 57. También el caso del Ermitage, San Petersburgo, cuyo director, Michaël Piotrovski, comenzó una gira por Estados Unidos en 1990, buscando financiación a cambio del alquiler de las colecciones. Ver Adré Gob, Le musée, une institution dépasée?, p. 63. 
enajenen esa tradición cultural que recuerda a todos la época en que París fue el centro del mundo y hasta allí llega su vocación nacionalista. Clair ha sufrido el desencanto del arte contemporáneo y se refugia en los pequeños museos poco visitados donde sacia su gusto elitista, porque en el fondo hay en Clair un sentimiento contradictorio, una revulsión inocultable por el arte experimental actual. Para el crítico el mundo del arte se divide en dos, el de la gran tradición francesa guardada en sus museos y el "arte" contemporáneo de estética relativista. Pero el problema no radica solo en la concepción materialista que ha entrado al museo. No. Es artístico y tiene que ver con lo que los artistas contemporáneos creen que es el arte, con el relativismo de los valores estéticos que practican y que han empujado al arte hasta los confines de la nada. Frente a esta situación gente de la generación de Clair sufre el desencanto resumido en el verso de Manrique "cualquiera tiempo pasado fue mejor" y se refugian en la tradición y el nacionalismo. Sin embargo hay que considerar que Clair y sus congéneres, quizás involuntariamente, contribuyeron en cierta medida a la ruptura con la tradición cuando proponía en los años setenta rendre l'ouvre á la libre circulation du désir. Idea que aplicada a la museografía buscaba una interactividad con el visitante, pero que malinterpretada por las vanguardias post duchampnianas propugnaron la desaparición del oficio y la técnica a favor de lo conceptual haciendo posible que cualquier propuesta sea considerada arte y que cualquier persona sea artista. Frente a esta desviación -según Clair- el Louvre seguirá siendo el templo donde se guarda lo más granado de la tradición de Occidente y sus soldados custodios no pueden hacer menos que protestar con todas sus fuerzas.

\section{Arquitectura de marca: los nuevos museos}

Así pues, dos hechos notorios tienen que ver de alguna manera con el museo contemporáneo, y más precisamente con la tendencia de construir nuevos edificios: una nueva acepción de la palabra economía aplicada a los bienes culturales como economía de lo inmaterial y la paulatina desaparición del "arte", entendido éste como oficio y/o técnica, en camino hacia lo puramente conceptual. ¿En qué manera el concepto de economía de lo inmaterial afecta al museo actual? Al ponerse en práctica los proyectos de alquiler de las colecciones y marcas se abre el camino de la "desnacionalización", que es como decir "despersonalización”; dejar de lado las características de la cultura que la hacen diferente de otras. Hablar de una cultura universal es hablar de una homogenización descolorida que obvia las diferencias y los matices. Por otro lado se alienta la construcción de museos sin colección, meros repositorios provisionales y salas temporales al servicio de eventos transitorios.

Hay que tener en cuenta que el arte ha llegado a una situación crítica, a un estancamiento a causa de la ola conceptualista. Nadie pudo imaginar que la propuesta de ese genio burlón que fue Duchamp tendría como consecuencia la desaparición del soporte, de la materialidad y la operatividad artística. El alcance de su idea iconoclasta no afectó a su “obra”, celosamente guardada en el museo de Filadelfia, pero si influyó en jóvenes artistas como, Lawrence Weiner (1940) o Joseph Kosuth (1945), pertenecientes a la primera generación de artistas conceptuales. Es sabido que este grupo, al que se puede sumar Robert Barry (1936), Douglas Huebler (1924-77), Robert Morris (1931), propugnaba la disolución material de la obra hacia la sola nominación verbal. Si la obra es el concepto no es necesario construir lugares donde pueda exhibirse. Seth Siegelaub, promotor del grupo dijo: "Hacemos la exposición en una oficina; no tenemos necesidad de una galería. Exponemos material impreso. Nuestras obras son efímeras, definidas solo temporalmente, basadas en un texto y no tienen necesidad de alguna institución material". ${ }^{15}$

Hasta qué punto el conceptualismo ha influido en la arquitectura de museos puede verse en dos ejemplos paradigmáticos, el Museo Nacional para el arte del siglo XXI, en Roma, y

15 Hal Foster et alt. Arte del 1900, Zanichelli editori, Milano, 2006, pp. 528-529. 


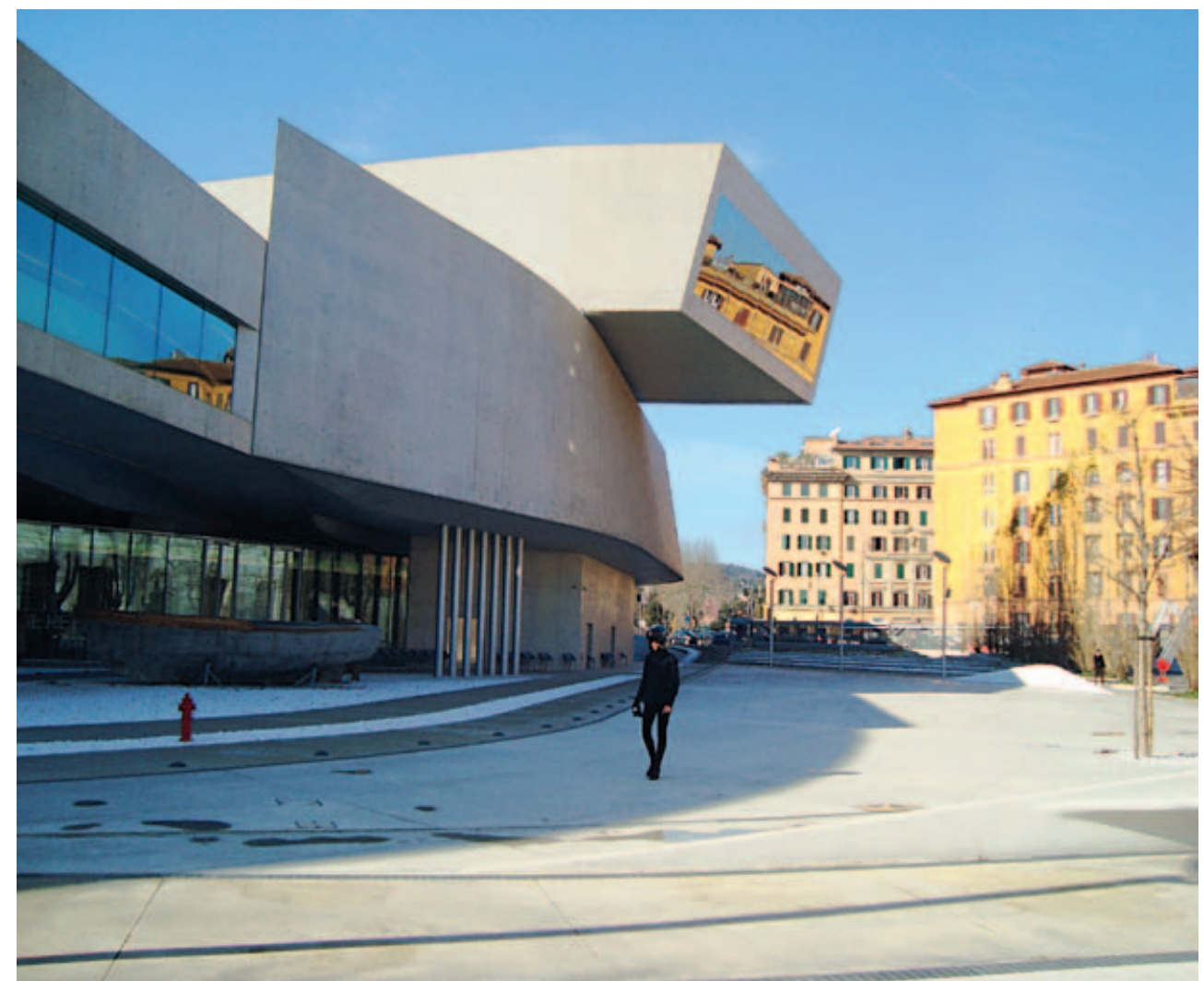

Vista exterior del Museo Nacional de Arte del Siglo XXI (MAXXI).

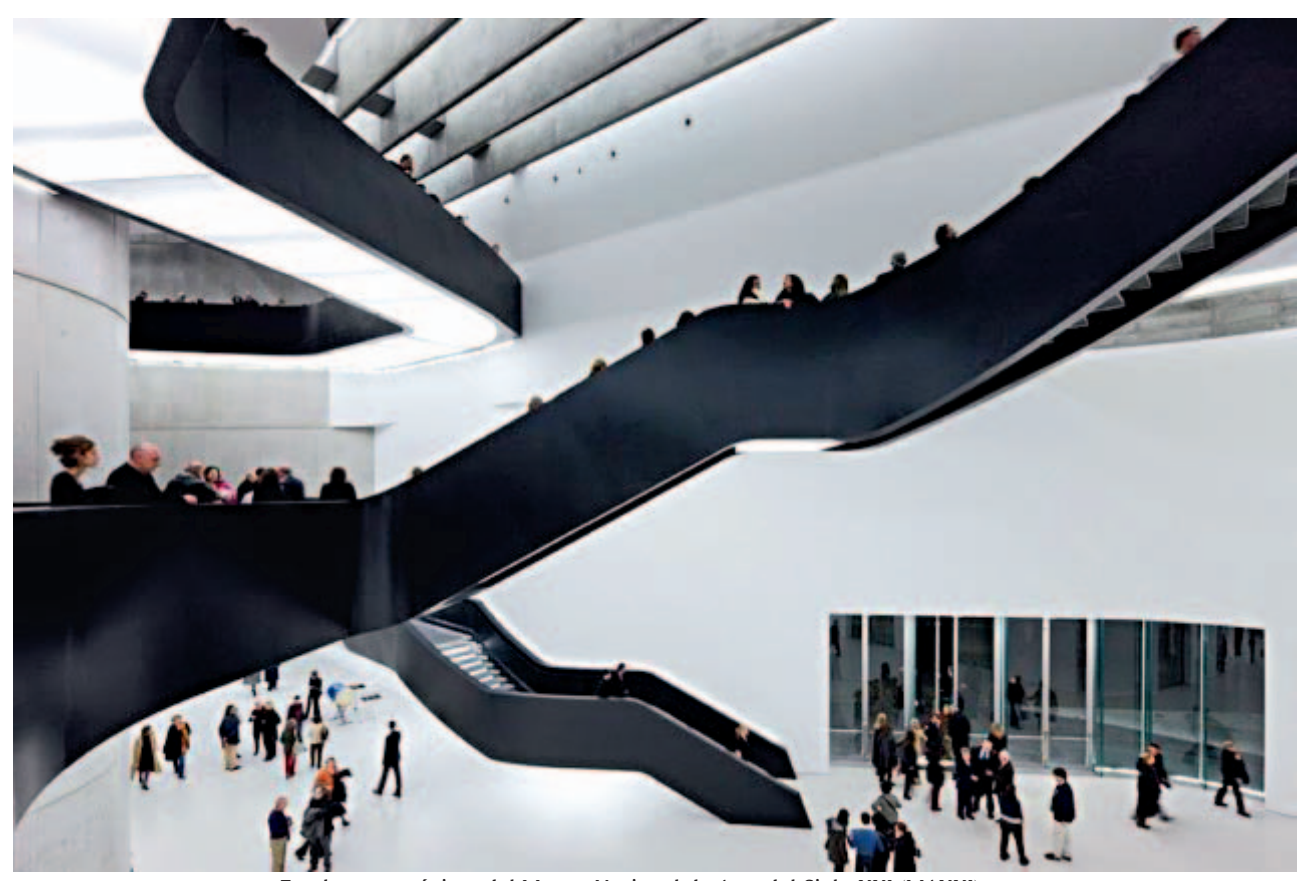

Escaleras mecánicas del Museo Nacional de Arte del Siglo XXI (MAXXI). 


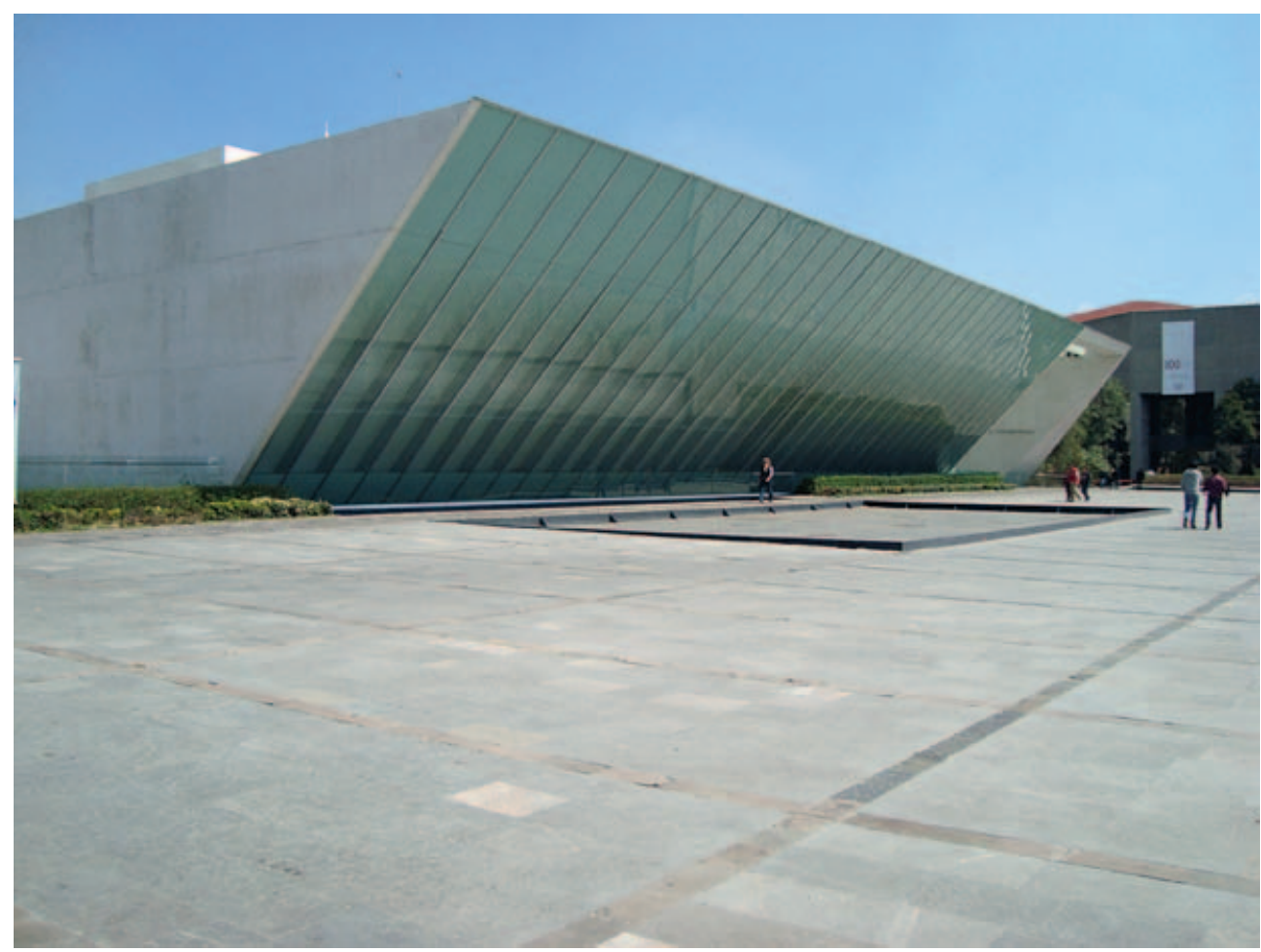

Vista exterior del Museo Universitario de Arte Contemporáneo de la UNAM, México, arq. Teodoro Gonzáles de León. 2008.

el Museo de Arte Contemporáneo de la Universidad Nacional Autónoma de México. El primero, diseñado por la arquitecta Zaha Hadid y construido entre 2003 y 2010 con un costo de 150'000.000 euros, presenta un entramado de rampas y pasarelas que impresionan al visitante desde que entra. El segundo, proyectado por el arquitecto Teodoro González de León, inaugurado el 2008, apuesta también por la sorpresa con una monumental vidriera, inclinada en ángulo agudo sobre la plaza. Pero al interior se observa en ambos la pobreza de lo exhibido. La excusa es comprensible: dirán que los dos son museos de arte contemporáneo y como tales están formando sus colecciones, aunque el de México declara que colecciona a partir del año 1952. Así, en las salas de estos museos, por ahora, el público

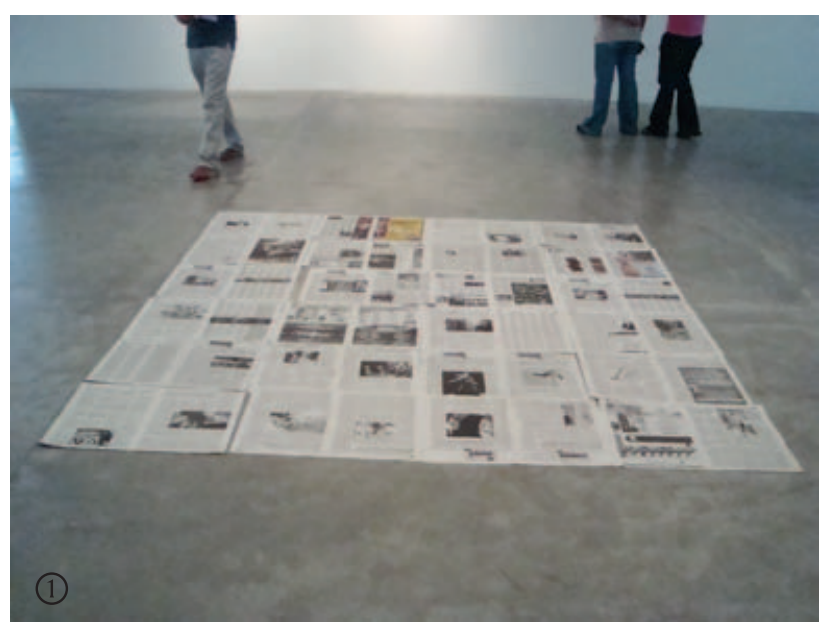
se tiene que resignar a ver lo que producen los artistas en nuestros días: hojas de papel periódico extendidas en el suelo, grandes esferas de papier maché, textos pegados en la pared, etc., y el desánimo nos invade al pensar en la colección que lograrán concentrar estos museos, a la que seguramente se dedicarán sesudos estudios y ediciones de lujo. En mi opinión, el único país que ha construido el local que se merecía ha sido Grecia, con su monumental 
museo de la Acrópolis ${ }^{16}$, que aunque les ha costado una millonada en momentos en que se veía venir la crisis del euro, era el momento obligado de hacerlo, para darle a la valiosa colección un lugar digno de la belleza e importancia de sus piezas seculares.

Frente a estos ejemplos cabe preguntarse iqué pasa en el Perú en relación al futuro de sus museos? Por un lado debemos admitir que nuestro atraso proverbial respecto a los centros vanguardistas nos está librando de las tentaciones liberales de alquilar nuestras colecciones a los países desarrollados ${ }^{17}$. Aunque esta idea podría estar dando vueltas por la cabeza de algún empresario moderno para fundar "le petit Sipán" en algún emirato árabe, los peruanos somos todavía muy nacionalistas y protestaríamos en forma masiva frente a tal despropósito. Por otro lado, lo bueno que ha traído la posmodernidad por estos lares ha sido que, desde más o menos el año 1975, el arte y la cultura populares han sido reconocidos
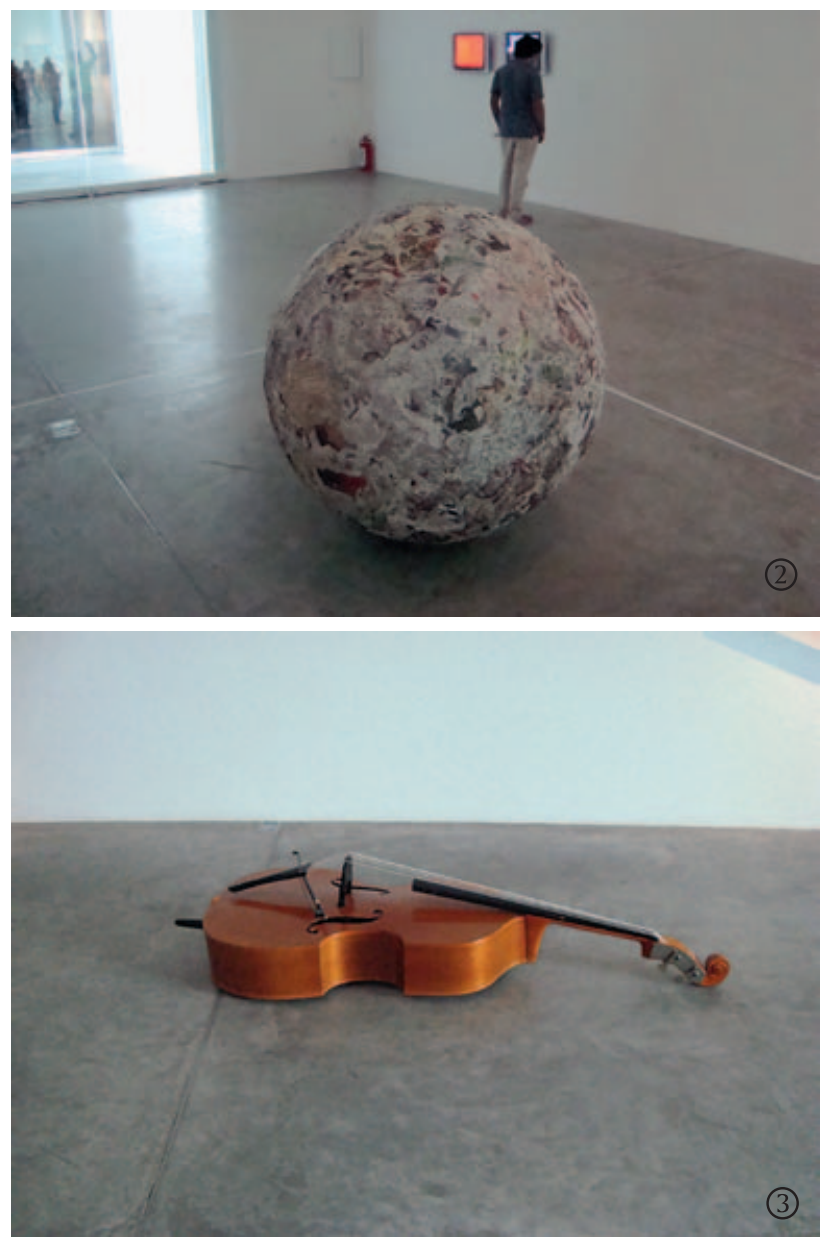

(Fotos 1, 2 y 3). Muestra de arte conceptual en las instalaciones del Museo Universitario de Arte Contemporáneo de la UNAM. 2011. e incluidos como pequeños relatos frente a la Historia del Arte Universal. Esto ha propiciado una revalorización de nuestra cultura y la tarea pedagógica del museo orientado a la inclusión de las mayorías. Necesitamos pues de nuestras colecciones; pero, lo que si debe cambiar es el enfoque y el sentido que debemos darle al patrimonio. Dejar por fin los grandes relatos homogenizadores para presentar una historia de las partes, los héroes anónimos, la vida diaria, los valores y desvalores, la salud, la alimentación, etc., dejar la presentación de las cimas a favor de la incursión en los valles. Solo así dejaremos de crear falsas historias para enfrentarnos descarnadamente a la realidad con lo bueno y lo malo que tenemos.

16 Diseñado por el arquitecto Bernad Tchumi (1944) e inaugurado en 2010.

17 Las exposiciones arqueológicas propiciadas por el Estado peruano no tienen carácter venal y cumplen el rol de embajadoras del Perú aunque, hay que reconocerlo, las colecciones cerámicas y textiles son las que se perjudican debido al transporte. 